\title{
Effect of Reactor Design on the Plasma Treatment of NOx
}

\author{
C.R. McLarnon \\ B.M. Penetrante
}

This paper was prepared for submittal to the

1998 Society of Automotive Engineers

Fall Fuels and Lubricants Meeting

San Francisco, $\mathrm{CA}$

October 19-22, 1998

August 1998

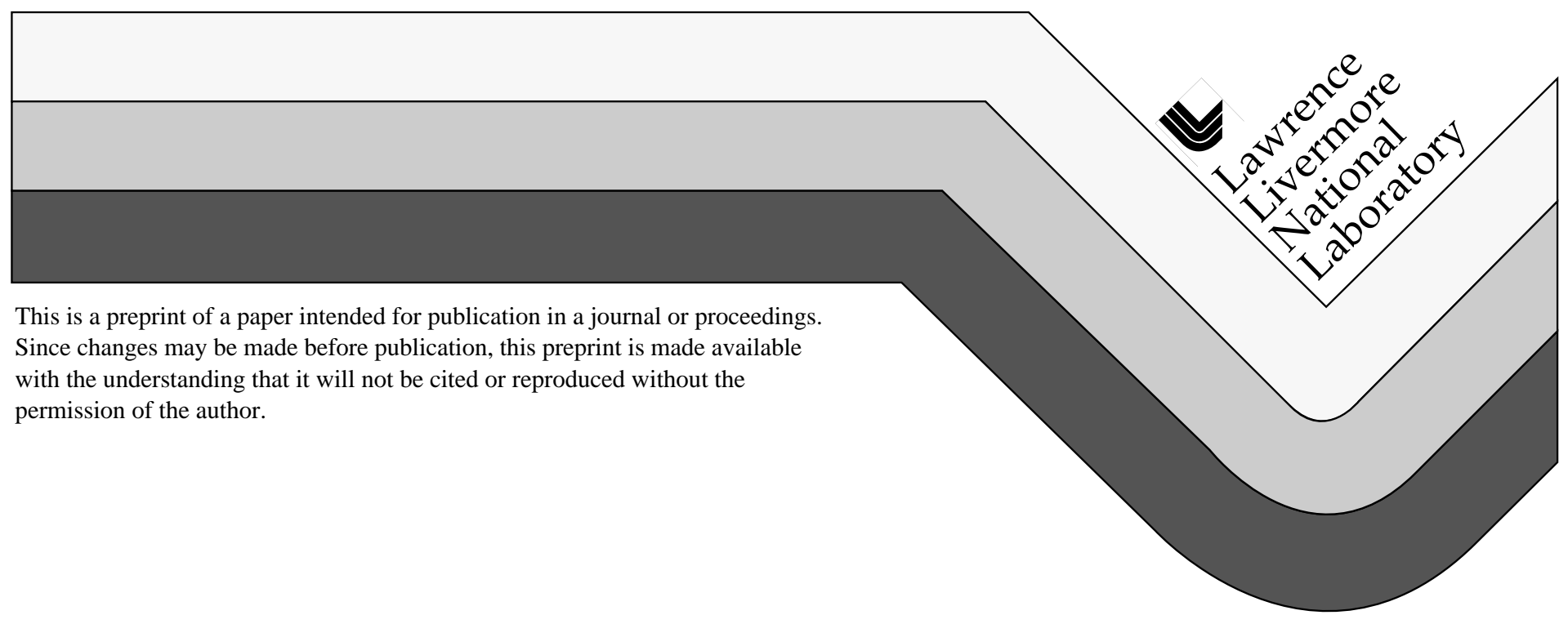




\section{DISCLAIMER}

This document was prepared as an account of work sponsored by an agency of the United States Government. Neither the United States Government nor the University of California nor any of their employees, makes any warranty, express or implied, or assumes any legal liability or responsibility for the accuracy, completeness, or usefulness of any information, apparatus, product, or process

disclosed, or represents that its use would not infringe privately owned rights. Reference herein to any specific commercial product, process, or service by trade name, trademark, manufacturer, or otherwise, does not necessarily constitute or imply its endorsement, recommendation, or favoring by the United States Government or the University of California. The views and opinions of authors expressed herein do not necessarily state or reflect those of the United States Government or the University of California, and shall not be used for advertising or product endorsement purposes. 


\title{
Effect of Reactor Design on the Plasma Treatment of $\mathbf{N O}_{\mathbf{x}}$
}

\author{
Christopher R. McLarnon \\ Zero Emissions Technology \\ Bernie M. Penetrante \\ Lawrence Livermore National Laboratory
}

Copyright (C) 1998 Society of Automotive Engineers, Inc.

\begin{abstract}
This paper presents the results of experiments in which various parameters were varied systematically in an attempt to understand how the reactor design affects the energy efficiency for plasma processing of $\mathrm{NO}_{\mathrm{x}}$. These parameters include the packing material, electrode diameter, and voltage frequency. It is shown that the applied voltage is not the relevant parameter when comparing the performance of different plasma reactors. The important control parameter is the input energy density. In accordance with the observations reported by Penetrante et al. [Applied Physics Letters 68, 3719-3721 (1996)], we have found that reactor design has little influence on the basic energy consumption of the plasma. Consequently, different reactor designs should yield basically the same plasma chemistry if the experiments are performed under identical gas composition and temperature conditions.
\end{abstract}

\section{INTRODUCTION}

A critical issue in the use of plasmas for the treatment of $\mathrm{NO}_{\mathrm{X}}$ is the electrical energy consumption. Whether the plasma is used to directly reduce $\mathrm{NO}_{\mathrm{X}}$ in the gas phase, or utilized to produce partial oxidation intermediates that enhance the heterogeneous removal of $\mathrm{NO}_{\mathbf{X}}$, the electrical energy consumption of the process is a concern. Many ideas have been proposed in attempts to minimize the electrical energy consumption, including (a) optimization of the electrode structure of the plasma reactor, and (b) optimization of the voltage waveform applied to the plasma reactor. It has been difficult to assess and compare the performance of various kinds of plasma reactors. The data presented in the literature using different kinds of reactors often were measured under different gas conditions. In many cases, the data are presented in a way that makes it impossible for the reader to determine the energy consumption of the reactor.

This paper will present the results of experiments in which various parameters were varied systematically in an attempt to understand how the reactor design affects the energy efficiency for plasma processing of $\mathrm{NO}_{\mathrm{x}}$. These parameters include the packing material, electrode diameter, and voltage frequency.

Many papers in the plasma processing literature present their $\mathrm{NO}_{\mathrm{x}}$ conversion efficiency as a function of the voltage applied to the plasma reactor. We will show that the applied voltage is not the relevant parameter when comparing the performance of different plasma reactors. Comparisons based on the applied voltage lead to erroneous conclusions. The important control parameter is the energy density delivered to the plasma. We will further show that reactor design has little influence on the basic energy consumption of the plasma. Consequently, different reactor designs should yield basically the same plasma chemistry if the experiments are performed under identical gas composition and temperature conditions.

\section{EXPERIMENTAL CONDITIONS}

When dealing with complicated gas mixtures encountered in real exhaust gases, it is often difficult to separate the plasma physics issues affecting electrical energy consumption in the plasma reactor from the plasma chemistry issues affecting the $\mathrm{NO}_{X}$ conversion chemistry. In comparing the effects of electrical and reactor parameters, it is important to carry out simplified experiments in which the number of chemical components is limited. A gas mixture consisting of dilute concentration of $\mathrm{NO}$ in $\mathrm{N}_{2}$ provides a good system for studying the effect of reactor parameters on the electron kinetics in the plasma. In this mixture the overall NO removal mechanism is determined by only a few reactions and the simplicity of the gas mixture allows a precise analysis of the process products. The oxygen balance in the system can be established to confirm that all the products of the plasma processing are accounted for. The analysis of the basic electrical energy consumption is also greatly simplified because the input energy is consumed only in electron-impact reactions with $\mathrm{N}_{2}$. 
All of the experimental results discussed here were obtained using a mixture of dilute concentration of $\mathrm{NO}$ in $\mathrm{N}_{2}$. In this gas mixture the destruction of $\mathrm{NO}$ results mainly in the formation of $\mathrm{N}_{2}$ and $\mathrm{O}_{2}$, with only small amounts of $\mathrm{NO}_{2}$ and $\mathrm{N}_{2} \mathrm{O}$. The $\mathrm{NO}_{\mathrm{x}}$ conversion for the NO- $\mathrm{N}_{2}$ system can therefore be taken as the percentage of $\mathrm{NO}_{\mathrm{X}}$ reduction to $\mathrm{N}_{2}$.

The plasma reactor used in the experiments reported here is a dielectric-barrier discharge reactor. The reactor geometry was one of concentric cylinders. The center and outer cylinders were a solid stainless steel rod and stainless steel tube. A high voltage AC power was applied between the electrodes, with the outer electrode tube at ground potential. Various diameter center electrodes were used, ranging from $0.1 \mathrm{~mm}$ to $4 \mathrm{~mm}$. The inner diameter of the outer electrode tube ranged from $22 \mathrm{~mm}$ to $25 \mathrm{~mm}$. Dielectric barriers made of quartz were placed adjacent to the center and outer electrodes. One was used to cover the inner electrode and the other was used to cover the inside of the outer electrode. The length of the plasma reactor tube was $30.5 \mathrm{~cm}$. The discharge plasma region could be made shorter than the tube by limiting the length of the center electrode inside the center dielectric barrier, which ran the full length of the reactor and provided mechanical support for the electrode. A sketch of the plasma reactor is shown in Figure 1.

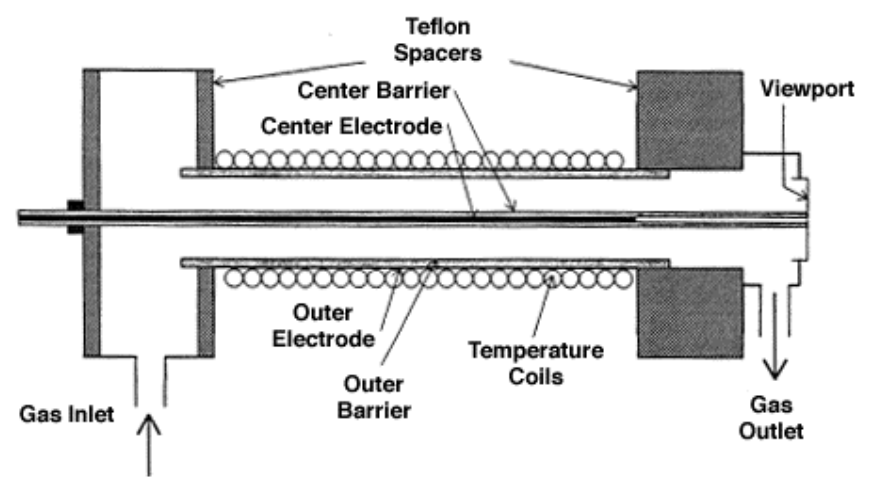

Figure 1. Sketch of the dielectric-barrier discharge reactor used in this study.

High voltage $A C$ power was supplied to the plasma reactor. A variable voltage $(0-120 \mathrm{~V})$, variable frequency $(20-20,000 \mathrm{~Hz})$ power supply was used to power a high voltage transformer. The transformer was rated at a primary voltage of $120 \mathrm{~V}$, a secondary voltage of $25 \mathrm{kV}$ and a power limit of $0.5 \mathrm{KVA}$. The power supply and the power measurement is discussed in detail in an accompanying paper [1].

To characterize the electrical energy consumption of the process, the composition of the effluent gas was recorded as a function of the input energy density. The input energy density, in units of Joules per standard liter $(\mathrm{J} / \mathrm{L})$, is the ratio of the power (deposited into the gas) to gas flow rate at standard conditions $\left(25^{\circ} \mathrm{C}\right.$ and $\left.1 \mathrm{~atm}\right)$.

The composition of the effluent gas was also recorded as a function of other parameters such as applied voltage, voltage frequency and gas flow rate. There are authors who show comparisons of plasma reactor performance in terms of the applied voltage. We will present our data also in this manner in order to point out that comparisons based on the applied voltage lead to erroneous conclusions. The important control parameter that should be used for comparing plasma reactor performance is the input energy density.

A chemiluminescent $\mathrm{NO}_{x}$ analyzer was used to measure the concentration of oxides of nitrogen in the gas stream entering or exiting from the reactor. The difference between $\mathrm{NO}$ and $\mathrm{NO}_{\mathrm{x}}$ readings was taken to be $\mathrm{NO}_{2}$.

$\mathrm{N}_{2} \mathrm{O}$, a possible product in plasma processing of $\mathrm{NO}$, could not be detected by the NOx analyzer. A HewlettPackard 5890 Series II gas chromatograph with a thermal conductivity detector was used to determine if $\mathrm{N}_{2} \mathrm{O}$ was present in the reactor exit gas. A 9' by $1 / 8$ " stainless steel column packed with 50/80 mesh Porapak $\mathrm{T}$ was used to separate $\mathrm{N}_{2} \mathrm{O}$ from the other gases in the stream.

\section{CHEMICAL KINETICS}

For dilute concentrations of $\mathrm{NO}$ in $\mathrm{N}_{2}$, the input energy required for NO reduction [2-4]:

$$
\mathrm{N}+\mathrm{NO} \rightarrow \mathrm{N}_{2}+\mathrm{O}
$$

is determined by the energy required for dissociation of $\mathrm{N}_{2}$ [5]:

$$
\mathrm{e}+\mathrm{N}_{2} \rightarrow \mathrm{e}+\mathrm{N}+\mathrm{N}
$$

The input electrical energy is consumed in electronimpact reactions with $\mathrm{N}_{2}$ and the removal of $\mathrm{NO}$ proceeds mainly via reduction by the $\mathrm{N}$ atom [6]. By doing experiments using this mixture it is therefore possible to examine the dependence of the dissociation rate of $\mathrm{N}_{2}$ on the plasma reactor configuration. The dissociation rate of $\mathrm{N}_{2}$ provides a good measure of the electron mean energy in the plasma. In turn, the electron mean energy provides a measure of the effective $E / n$ that is established in the plasma. $E / n$ is the electric field strength divided by the total gas density.

The calculated G-value (number of $\mathrm{N}_{2}$ dissociations per $100 \mathrm{eV}$ of input energy) and electron mean energy as a function of $E / n$ is shown in Figure 2. In the NO- $\mathrm{N}_{2}$ mixture, the number of $\mathrm{N}_{2}$ dissociations in the plasma can be easily related to the number of NO molecules 
reduced from the gas. Thus, by measuring the amount of NO reduction, we can get a measure of the electron mean energy in the plasma. We will see that the experimental results presented in this paper all correspond to an electron mean energy between 3.0 and $3.5 \mathrm{eV}$.

A chemical kinetics analysis of the important reactions during plasma processing of $250 \mathrm{ppm} \mathrm{NO}$ in $\mathrm{N}_{2}$ is shown in Figure 3. Details of the model are discussed by Penetrante et al. [2-3]. The dominant reaction in this mixture is the reduction of $\mathrm{NO}$ to $\mathrm{N}_{2}$ via reaction (1). The $\mathrm{O}$ atom resulting from reaction (1) oxidizes $\mathrm{NO}$ to $\mathrm{NO}_{2}$ :

$$
\mathrm{O}+\mathrm{NO}+\mathrm{M} \rightarrow \mathrm{NO}_{2}+\mathrm{M}
$$

The $\mathrm{NO}_{2}$ is reduced back to $\mathrm{NO}$ :

$$
\mathrm{O}+\mathrm{NO}_{2} \rightarrow \mathrm{NO}+\mathrm{O}_{2}
$$

thus resulting in a small amount of $\mathrm{NO}_{2}$ product. The reduction of $\mathrm{NO}_{x}$ by the $\mathrm{N}$ atom is limited by the electron-impact dissociation of $\mathrm{N}_{2}$.

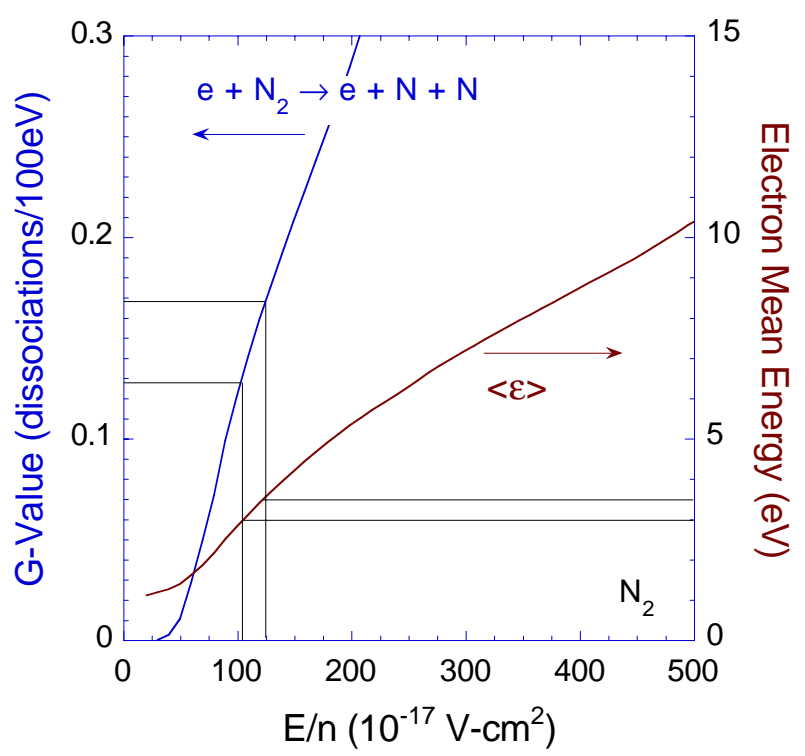

Figure 2. Calculated $\mathrm{N}_{2}$ dissociation $\mathrm{G}$-value and electron mean energy as a function of effective $E / n$ in the plasma.

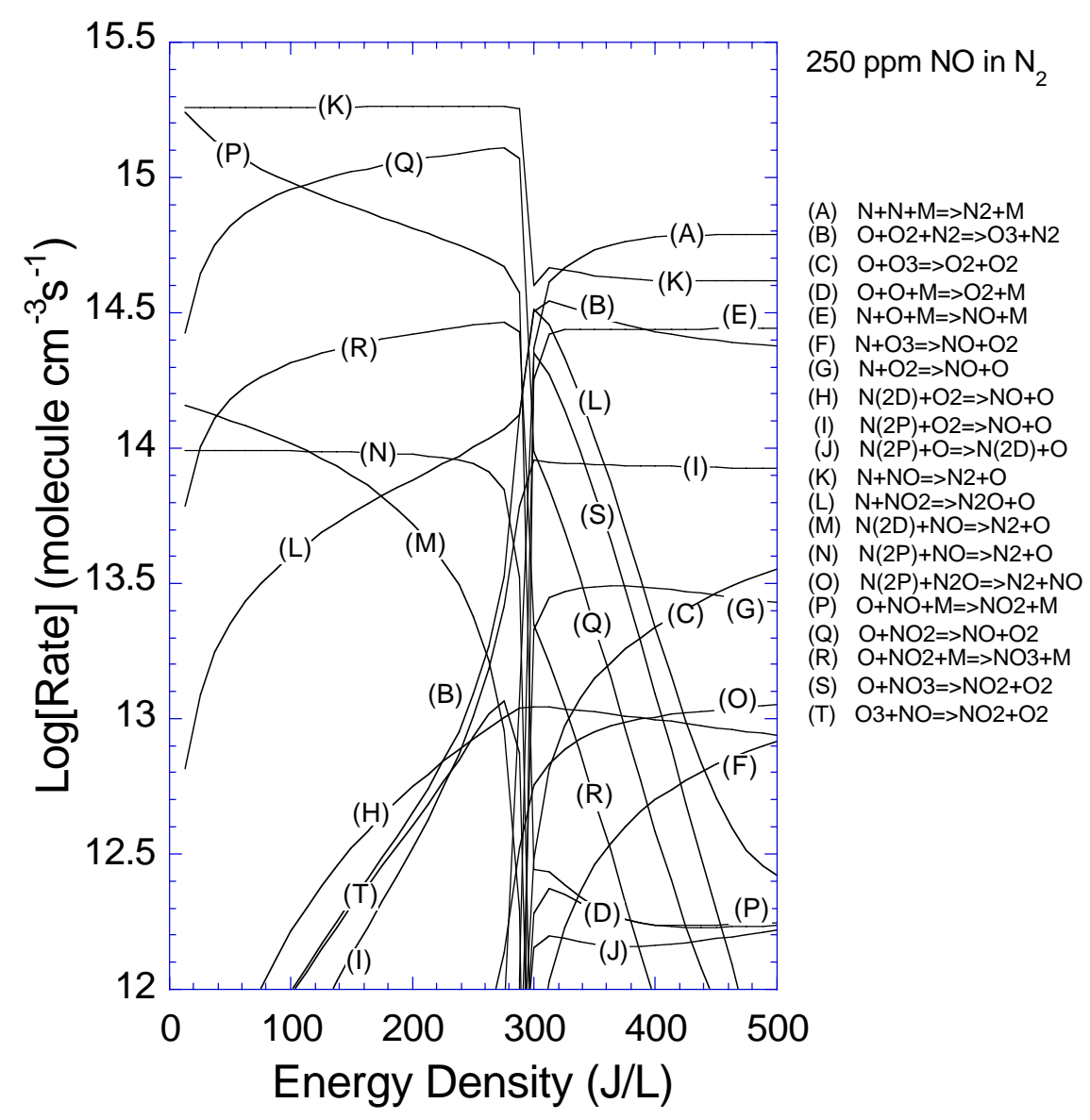

Figure 3. Chemical kinetics analysis of the important reactions during plasma processing of $250 \mathrm{ppm} \mathrm{NO}$ in $\mathrm{N}_{2}$. 
Figure 3 shows that the removal of $\mathrm{NO}$ is dominated by the reduction reaction $\mathrm{N}+\mathrm{NO} \rightarrow \mathrm{N}_{2}+\mathrm{O}$; thus, the energy cost for reduction of $\mathrm{NO}$ is simply the energy cost for production of $\mathrm{N}$. The only two other important reactions are the oxidation of $\mathrm{NO}$ to $\mathrm{NO}_{2}$ via $\mathrm{O}+\mathrm{NO}+$ $\mathrm{M} \rightarrow \mathrm{NO}_{2}+\mathrm{M}$, and the reduction of $\mathrm{NO}_{2}$ to $\mathrm{NO}$ via $\mathrm{O}+$ $\mathrm{NO}_{2} \rightarrow \mathrm{NO}+\mathrm{O}_{2}$. These two latter reactions serve to produce $\mathrm{O}_{2}$ as the only other major product in addition to $\mathrm{N}_{2}$. Most of the $\mathrm{NO}$ which are oxidized to $\mathrm{NO}_{2}$ are reduced back to NO; note that this happens only in the $\mathrm{NO}-\mathrm{N}_{2}$ mixture.

In Figure 3, NO is depleted at around $300 \mathrm{~J} / \mathrm{L}$. After the initial NO has been depleted, the concentration of $\mathrm{N}$ builds up until radical-radical reactions become important. Some of the $\mathrm{N}$ then recombine via $\mathrm{N}+\mathrm{N}+\mathrm{M}$ $\rightarrow \mathrm{N}_{2}+\mathrm{M}$; some of the $\mathrm{N}$ react with $\mathrm{O}$ to produce $\mathrm{NO}$ via $\mathrm{N}+\mathrm{O}+\mathrm{M} \rightarrow \mathrm{NO}+\mathrm{M}$. Any $\mathrm{NO}$ produced by the latter process are reduced by other $\mathrm{N}$ atoms.

There is very little $\mathrm{N}_{2} \mathrm{O}$ produced during the plasma processing of dilute mixtures of $\mathrm{NO}$ in $\mathrm{N}_{2}$. The most likely source of $\mathrm{N}_{2} \mathrm{O}$ is the reaction

$$
\mathrm{N}+\mathrm{NO}_{2} \rightarrow \mathrm{N}_{2} \mathrm{O}+\mathrm{O}
$$

In the NO- $\mathrm{N}_{2}$ mixture, there is little $\mathrm{N}_{2} \mathrm{O}$ produced for three reasons. First, the amount of $\mathrm{NO}_{2}$ formed is small. Second, the $\mathrm{N}$ atoms react preferentially with $\mathrm{NO}$, because the rate constant for $\mathrm{N}+\mathrm{NO}$ is larger, and the amount of $\mathrm{NO}_{2}$ is always small. Third, the $\mathrm{NO}_{2}$ produced in this system react preferentially with $\mathrm{O}$ (via reaction 4 ) instead of $\mathrm{N}$, and thus gets reduced to $\mathrm{NO}$ instead of $\mathrm{N}_{2} \mathrm{O}$.

\section{EFFECT OF PACKING}

The presence of solid materials in the gas space between the discharge electrodes alters the operation of the discharge plasma. Changes in the physical characteristics of the discharge can presumably cause variations in chemical reactions to occur.

A highly conductive material eliminates the discharge through the bulk of the gas region by eliminating the potential difference across the gas. Dielectric materials, on the other hand, provide a greater induced surface charge in the gas space for a given electrode geometry and applied voltage. Additionally, dielectric materials may provide numerous points for the microdischarges to occur, depending on the shape of the material. A high field intensity around the tip of a fiber with a high induced surface charge can produce a microdischarge more easily.

Experiments using several non-conducting materials were performed in this study to investigate their effect in conjunction with a barrier discharge plasma on the $\mathrm{NO}_{\mathrm{x}}$ conversion efficiency. The materials included cylindrical molecular sieves as well as glass wool and Kaowool in fiber form. The glass wool and Kaowool used were composed primarily of silica, while the molecular sieves were composed of aluminosilicates.

When the $\mathrm{NO}_{\mathrm{X}}$ reduction efficiency is plotted in terms of applied voltage, it appeared as if the $\mathrm{NO}_{X}$ reduction achieved using glass wool and Kaowool in fiber form were higher than that obtained using cylindrical molecular sieves. Additionally, the use of any of the three packing materials resulted in higher $\mathrm{NO}_{\mathrm{x}}$ reduction than when no packing was used.

The effect of glass wool packing on $\mathrm{NO}_{x}$ reduction was further investigated in a reactor at room temperature with an inlet gas mixture of $250 \mathrm{ppm} \mathrm{NO}$ in $\mathrm{N}_{2}$. Glass wool packings with densities of $0.12 \mathrm{~g} / \mathrm{cm}^{3}$ and $0.30 \mathrm{~g} / \mathrm{cm}^{3}$, as well as a system with no packing, were used. The results showing $\mathrm{NO}_{\mathrm{X}}$ reduction versus applied voltage for the three sets of experiments are shown in Figure 4. It appears as if the systems with glass wool packing resulted in higher $\mathrm{NO}_{\mathrm{X}}$ reduction than that without packing.

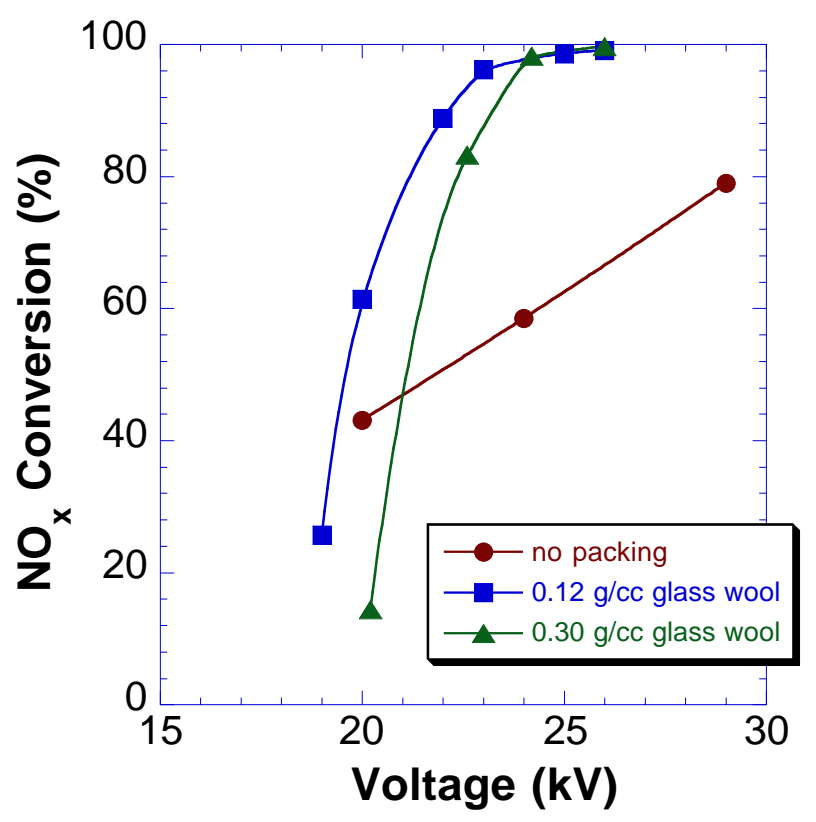

Figure 4. Effect of reactor packing on plasma processing of $250 \mathrm{ppm} \mathrm{NO}$ in $\mathrm{N}_{2}$.

Packing the reactor gas space results in a change in the electrical power input to the discharge plasma. The applied voltage is not a good parameter with which to compare the performance of different reactors. The input energy density (power input to the gas divided by the total gas flow rate) represents a more relevant physical scaling parameter. The results showing $\mathrm{NO}_{x}$ reduction versus input energy density for the same three sets of experiments are shown in Figure 5. Note that in terms of energy density input to the reactor, there was no 
significant difference in $\mathrm{NO}_{\mathrm{X}}$ reduction achieved in systems with no packing and those with glass wool packing. An increase in the density of the glass wool packing, and therefore an increase in glass wool surface area in the reactor, did not increase the $\mathrm{NO}_{\mathrm{x}}$ reduction for a given energy density input to the plasma.

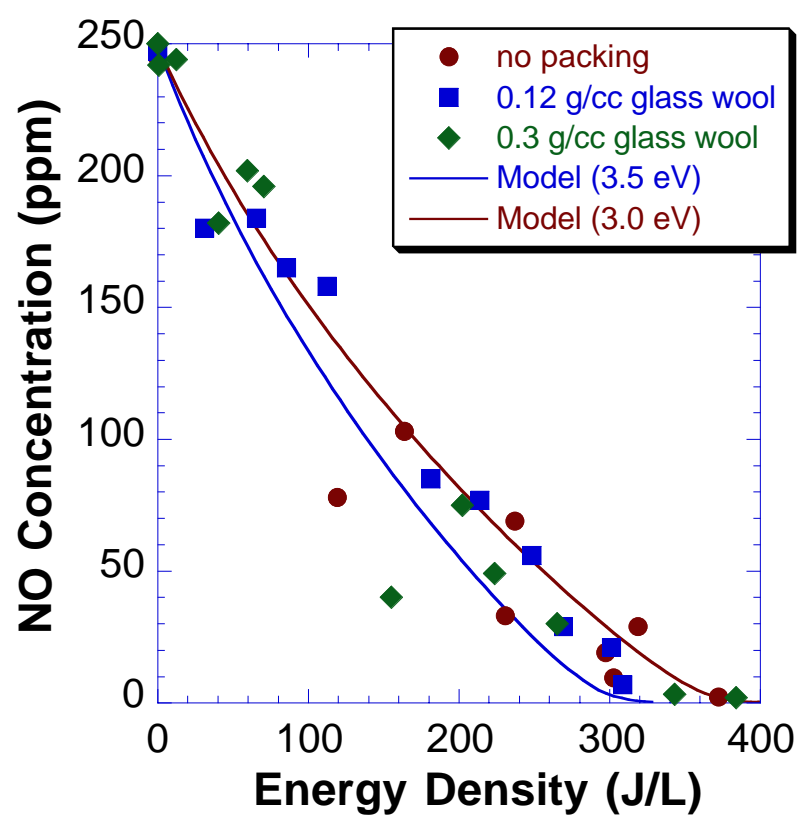

Figure 5. Effect of reactor packing on plasma processing of $250 \mathrm{ppm} \mathrm{NO}$ in $\mathrm{N}_{2}$.

Packing the reactor gas space with dielectric materials increased the capacitance of the reactor, which produced a greater charge concentration on the surface of the reactor electrodes for a given voltage. This was seen in the higher current measured for the packed reactor systems, prior to the onset of the discharge, than that measured without packing material in the reactor. The packed reactor's higher charge build-up also resulted in a higher discharge current and therefore higher power input to the reactor. It was this increase in power input to the reactor that was responsible for the higher levels of $\mathrm{NO}_{\mathrm{x}}$ reduction achieved (versus applied voltage) when the glass wool and Kaowool packings were used.

\section{EFFECT OF ELECTRODE DIAMETER}

Visual observations of the discharge plasma showed that the region of greatest discharge intensity occurred around the center electrode, where an intense blue glow was seen in the NO-N 2 system. At the outer electrode the visible glow was faint if it could be seen at all. This was due to the reduced current flux at the outer electrode brought about by the coaxial cylinder geometry. It was recognized that most of the gas in the reactor was outside the intense discharge region. Experiments with outer electrodes of reduced diameter were therefore conducted in an attempt to increase the percentage of the gas in the intense discharge region.

The effect on $\mathrm{NO}_{x}$ reduction of reducing the distance between electrodes by decreasing the outer electrode diameter from $25 \mathrm{~mm}$ to $22 \mathrm{~mm}$ was studied. A center electrode with a diameter of $4 \mathrm{~mm}$, surrounded by a quartz dielectric barrier ( $4 \mathrm{~mm}$ ID by $6 \mathrm{~mm} O D$ ) was used in each set of experiments. A second, outer quartz dielectric barrier, with a wall thickness of $1.5 \mathrm{~mm}$, was placed adjacent to the outer electrode in each configuration. The resulting annulus had an inner annulus diameter of $6 \mathrm{~mm}$ for both configurations, an outer annulus diameter of $22 \mathrm{~mm}$ for the $25 \mathrm{~mm}$ outer electrode, and an outer annulus diameter of $18 \mathrm{~mm}$ for the $22 \mathrm{~mm}$ outer electrode. The experiments were done at room temperature with an inlet gas mixture of 250 ppm $\mathrm{NO}$ in $\mathrm{N}_{2}$.

The results showing $\mathrm{NO}_{\mathrm{x}}$ reduction versus applied voltage for the two sets of experiments are shown in Figure 6.

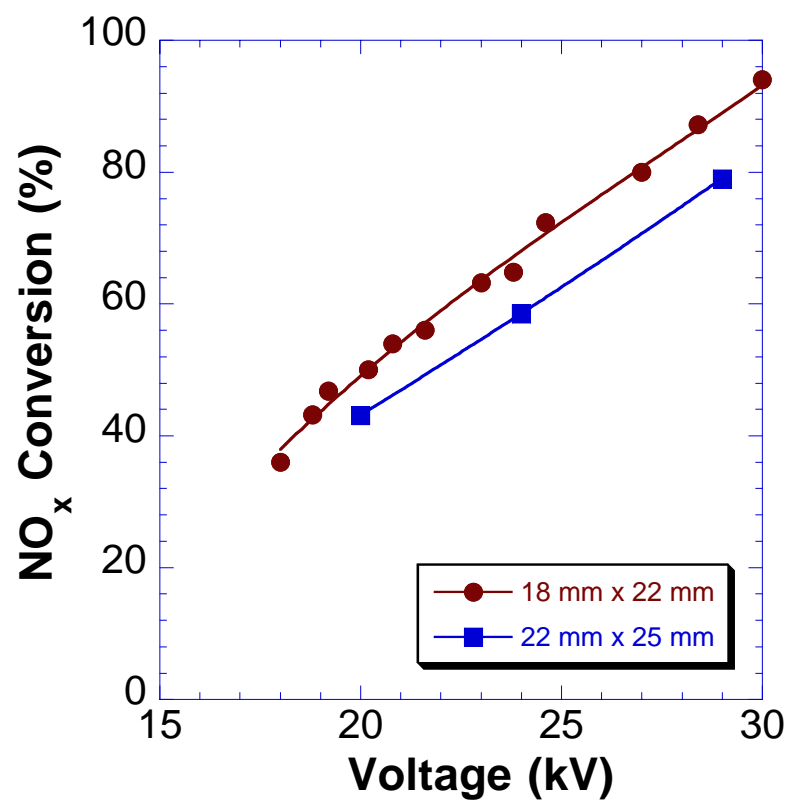

Figure 6. Effect of electrode diameter on plasma processing of $250 \mathrm{ppm} \mathrm{NO}$ in $\mathrm{N}_{2}$.

It appears as if the decrease in the electrode gap distance increased the $\mathrm{NO}_{\mathrm{x}}$ reduction. However, when the results are plotted in terms of the input energy density, it is clear that decreasing the diameter of the outer electrode or decreasing the electrode gap distance did not increase the $\mathrm{NO}_{x}$ reduction, as shown in Figure 7. The effect of reducing the gap spacing between the electrodes was to increase the power input to the reactor for a given voltage. Since the same center electrode system was used in both sets of experiments, the voltage at which the discharge initiated did not change. 


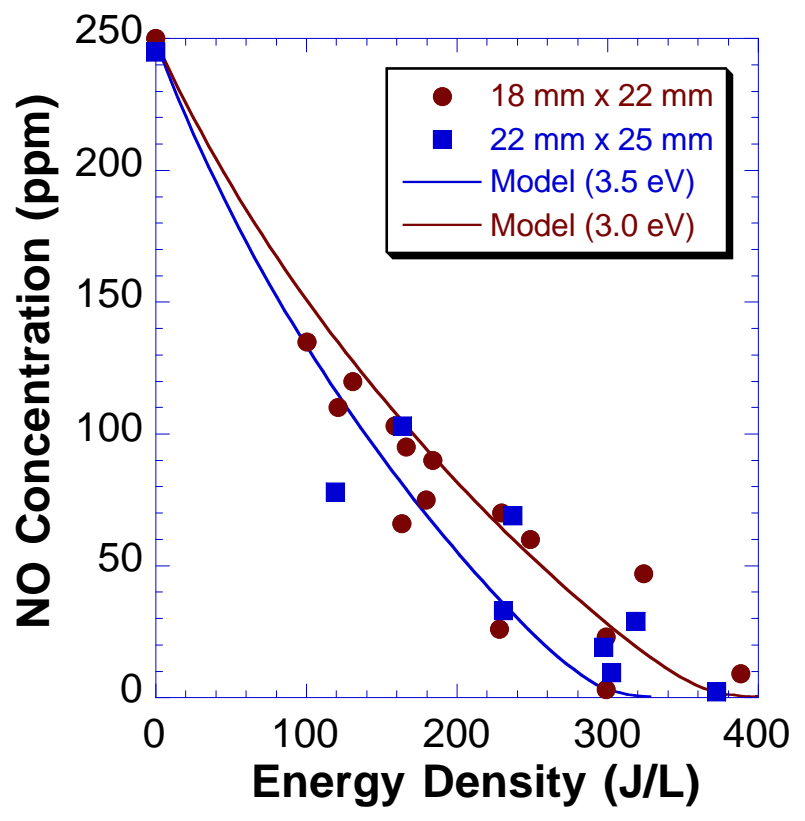

Figure 7. Effect of electrode diameter on plasma processing of $250 \mathrm{ppm} \mathrm{NO}$ in $\mathrm{N}_{2}$.

However, because of the reduced distance between the electrodes, the resistance of the gas was decreased and the induced surface charge for a given voltage increased (the capacitance increased) over that for the larger gap space. This resulted in a higher discharge current and greater discharge power for the smaller gap between electrodes.

\section{EFFECT OF FREQUENCY}

The effect of frequency on $\mathrm{NO}_{x}$ reduction was studied. The experiments were conducted using a glass wool packing of density $0.12 \mathrm{~g} / \mathrm{cm}^{3}$, and a gas mixture of 250 ppm NO in $\mathrm{N}_{2}$ at room temperature.

The results showing $\mathrm{NO}_{\mathrm{x}}$ reduction versus applied voltage at various frequencies are shown in Figure 8. The $\mathrm{NO}_{\mathrm{X}}$ reduction increased with frequency for a given voltage as the frequency was raised. The rate of increase in $\mathrm{NO}_{x}$ reduction versus voltage also increased as the frequency was increased.

When the results are plotted in terms of input energy density, it becomes clear that frequency does not affect the electrical power consumption to achieve a given level of $\mathrm{NO}_{\mathrm{X}}$ reduction, as shown in Figure 9. The effect of increasing frequency was to increase the power input for a given peak voltage, or to reduce the voltage required to achieve a given discharge power.

\section{SUMMARY OF DATA}

The experimental results shown in the previous sections suggest that the electron mean energy in the plasma reactor is very weakly dependent on reactor parameters

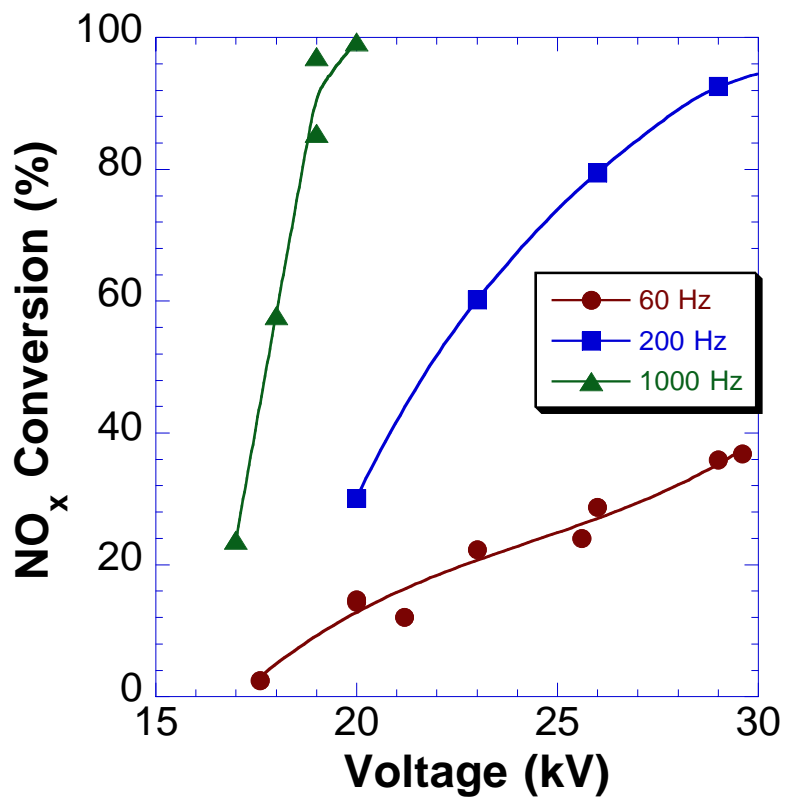

Figure 8. Effect of applied voltage frequency on plasma processing of $250 \mathrm{ppm} \mathrm{NO}$ in $\mathrm{N}_{2}$.

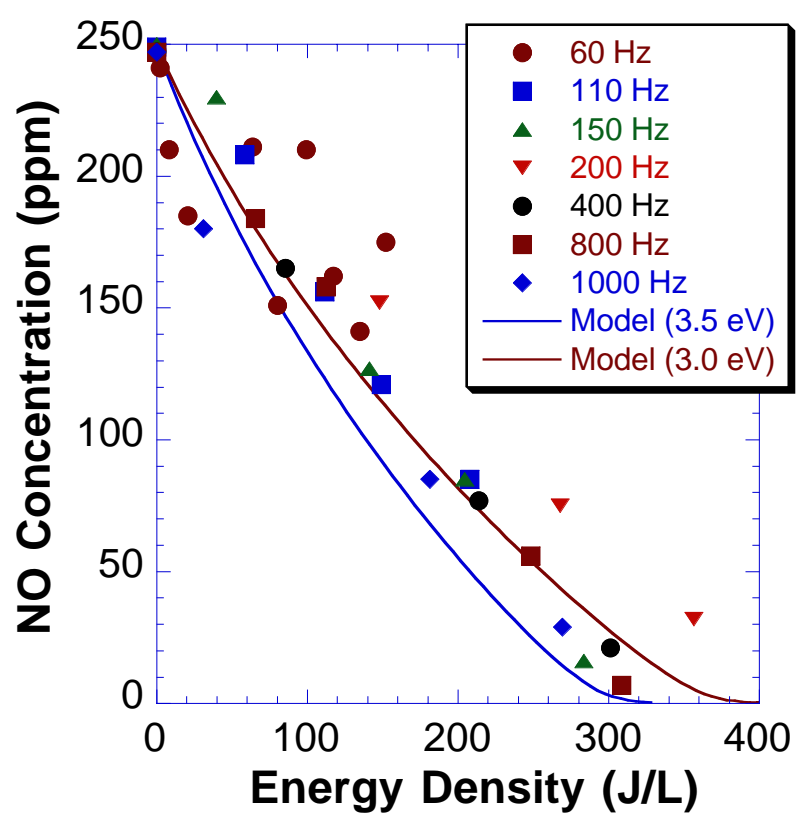

Figure 9. Effect of applied voltage frequency on plasma processing of $250 \mathrm{ppm} \mathrm{NO}$ in $\mathrm{N}_{2}$.

such as material packing, electrode gap spacing, and applied voltage frequency. A summary of all the data taken using a gas mixture of $250 \mathrm{ppm} \mathrm{NO}$ in $\mathrm{N}_{2}$ is shown in Figure 10.

\section{EFFECT OF INITIAL NO CONCENTRATION}

The results of other experiments on the NO-N $\mathrm{N}_{2}$ mixture using different initial NO concentrations are shown in Figures 11 and 12. These data consistently agree with 
calculations of the energy consumption for $\mathrm{NO}_{\mathrm{x}}$ reduction based on an electron mean energy in the plasma of $3.0-3.5 \mathrm{eV}$.

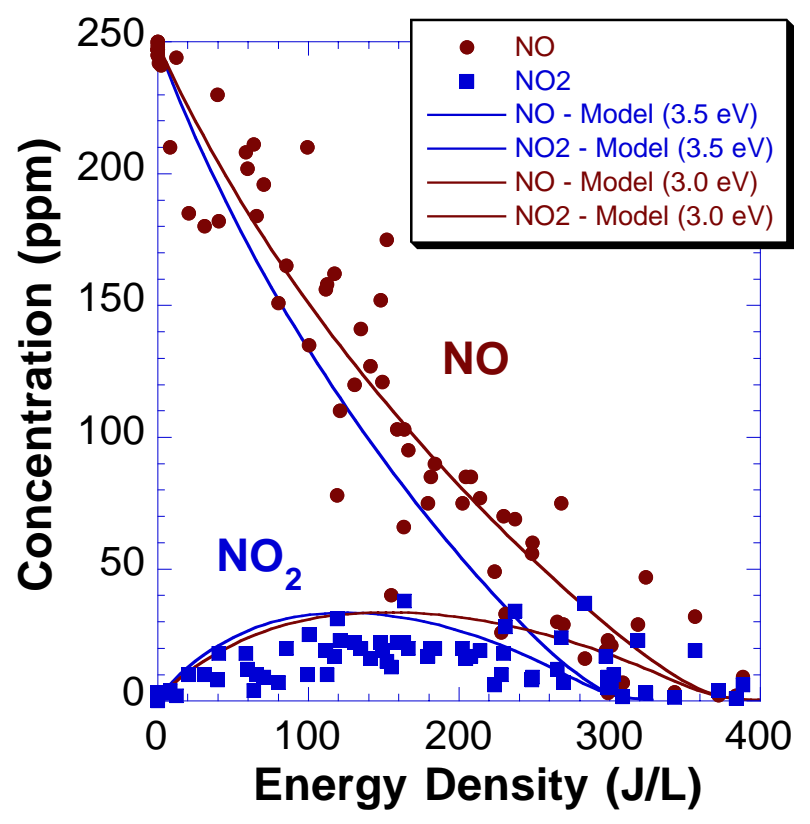

Figure 10. Summary of data on plasma processing of 250 ppm NO in $\mathrm{N}_{2}$.

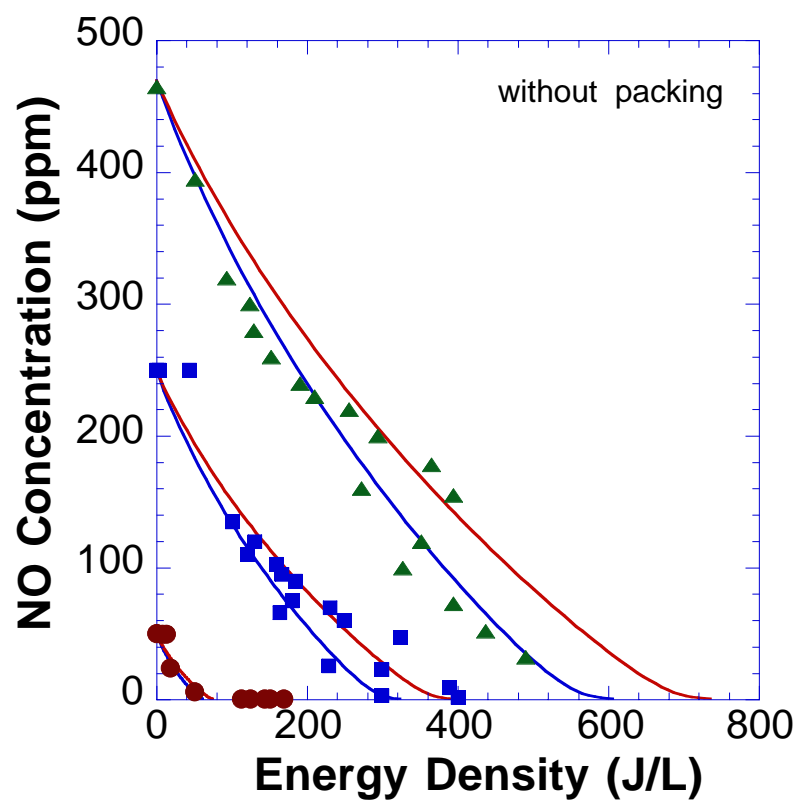

Figure 11. Effect of initial NO concentration on plasma processing of $\mathrm{NO}$ in $\mathrm{N}_{2}$. No packing in the plasma reactor.

\section{EFFECT OF REACTOR GEOMETRY}

The data presented here were obtained using dielectricbarrier discharge reactors consisting of concentric tubes.

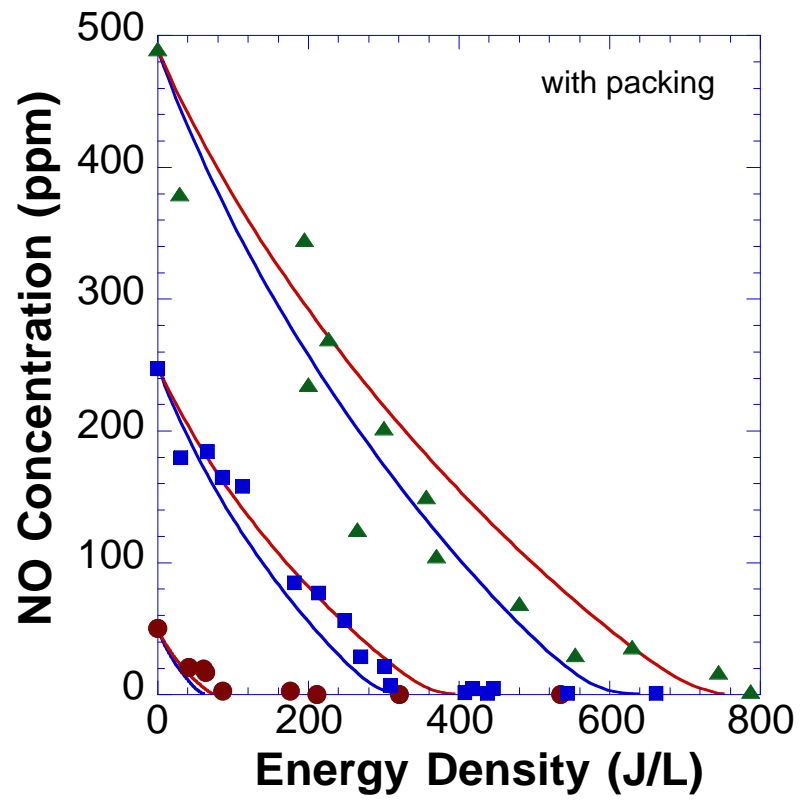

Figure 12. . Effect of initial NO concentration on plasma processing of $\mathrm{NO}$ in $\mathrm{N}_{2}$. With glass wool packing in the plasma reactor.

Penetrante et al. [4] has shown that there is no significant difference in the performance of planar and cylindrical reactors.

\section{CONCLUSIONS}

Experimental results on plasma processing of $\mathrm{NO}$ in $\mathrm{N}_{2}$ have been presented. The data have been obtained using different packing materials, electrode diameter, and voltage frequencies. We have shown that the applied voltage is not the relevant parameter when comparing the performance of different plasma reactors. Comparisons based on the applied voltage lead to erroneous conclusions. The important control parameter is the energy density delivered to the plasma.

We have found that reactor design has little influence on the basic energy consumption of the plasma. Consequently, different reactor designs should yield basically the same plasma chemistry if the experiments are performed under identical gas composition and temperature conditions.

\section{ACKNOWLEDGMENT}

This work was performed in part at Lawrence Livermore National Laboratory under the auspices of the U.S. Department of Energy under Contract Number W-7405ENG-48, with support from the Chemical Sciences Division of the DOE Office of Basic Energy Sciences. 


\section{REFERENCES}

1. McLarnon, C.R. and Penetrante, B.M., "Effect of Gas Composition in the $\mathrm{NO}_{x}$ Conversion Chemistry in a Plasma", SAE Paper 982433 (1998).

2. Penetrante, B.M., Hsiao, M.C., Merritt, B.T., Vogtlin, G.E. and Wallman, P.H., "Comparison of Electrical Discharge Techniques for Non-Thermal Plasma Processing of $\mathrm{NO}$ in $\mathrm{N}_{2}$.", IEEE Trans. Plasma Sci. 23, 679 (1995).

3. Penetrante, B.M., Hsiao, M.C., Merritt, B.T., Vogtlin, G.E., Wallman, P.H., Kuthi A., Burkhart, C.P., and Bayless, J.R., "Electron-Impact Dissociation of Molecular Nitrogen in Atmospheric-Pressure NonThermal Plasma Reactors", Appl. Phys. Lett. 67 , 3096 (1995).

4. Penetrante, B.M., Hsiao, M.C., Merritt, B.T., Vogtlin, G.E., Wallman, P.H., Neiger, M., Wolf, O., Hammer, T. and Broer, S., "Pulsed Corona and DielectricBarrier Discharge Processing of $\mathrm{NO}$ in $\mathrm{N}_{2}$ ", Appl. Phys. Lett. 68, 3719 (1996).

5. Cosby, P.C., "Electron-impact Dissociation of Nitrogen”, J. Chem. Phys. 98, 9544 (1993).

6. Clyne, M.A.A. and Thrush, B.A., "Rates of the Reactions of Nitrogen Atoms with Oxygen and with Nitric Oxide", Nature (London) 189, 56-57 (1961). 